\title{
A Inserção do Psicanalista em uma Unidade de Tratamento Intensivo
}

\author{
Alinne Nogueira Silva Coppus \\ Universidade Federal de Juiz de Fora, MG, Brasil.
}

\author{
Marcus Vinícius Rezende Fagundes Netto \\ Universidade de São Paulo, SP, Brasil.
}

Resumo: Levando-se em consideração a necessidade de publicações que aprofundem a possível articulação entre Psicanálise e Psicologia, juntamente com o fato de que cada vez mais o psicólogo/psicanalista é convocado a compor a equipe multidisciplinar de um hospital, este artigo discute e aprofunda as peculiaridades que permeiam a inserção deste profissional neste campo de trabalho. A partir de autores que tem como viés a leitura psicanalítica e do relato da singular experiência clínica em uma Unidade de Tratamento Intensivo (UTI), demarcamos a diferença entre entrada e inserção para que o psicólogo/psicanalista efetivamente tenha um lugar de atuação neste contexto. Além disso, chegamos à conclusão de que a produção de saber, a partir da clínica no hospital, pode possibilitar a criação da demanda de saber e, com isso, a inserção do analista via transferência de trabalho.

Palavras-chave: Psicanálise, Psicologia, Inserção, Hospitais.

\section{The Insertion of the Psychoanalyst in an Intensive Care Unit}

\begin{abstract}
Taking into consideration the need for publications showing the profound articulation between psychoanalysis and psychology, together with the fact that a psychologist/psychoanalyst is often asked to be part multi-professional team in a hospital; this study aims to discuss and to deepen the particularities that involve the insertion of this professional in this work field. Through the analysis of psychoanalytical authors and the brief account of the singular clinic experience in an Intensive Care Unit (ICU), we intended to establish a difference between insertion and entrance, so the psychologist/psychoanalyst can effectively work in this context. Furthermore, we come to the conclusion that the production of knowledge can facilitate the creation of a knowing demand and the insertion of the psychoanalyst, via working transference.

KeYwords: Psychoanalysis, Psychology, Insertion, Hospitals.
\end{abstract}




\title{
La inserción del Analista en una Unidad de Cuidado Intensivo
}

\begin{abstract}
Resumen:Tomando en cuenta la necesidad de publicaciones que profundicen la posible relación entre el psicoanálisis y la psicología, junto al hecho de que cada vez más se convoca al psicólogo/ psicoanalista para componer el equipo multidisciplinario de un hospital, este artículo aborda y profundiza las peculiaridades que permean la inserción de ese profesional en ese campo de trabajo. A partir de autores que tienen como perspectiva la lectura psicoanalítica y del relato de la singular experiencia clínica en una Unidad de Tratamiento Intensivo (UTI), delimitamos la diferencia entre entrada e inserción, para que el psicólogo/psicoanalista tenga, efectivamente, un lugar de actuación en ese contexto. Llegamos a la conclusión de que la producción de saber, a partir de la clínica en el hospital, puede posibilitar la creación de demanda de ese saber y, con eso, la inserción del analista por medio de la transferencia del trabajo.

Palabras clave: Psicoanálisis, Psicología, Inserción, Hospitales.
\end{abstract}

"Eu vivia como todo mundo, vendo a vida com os olhos abertos e cegos do homem, sem me espantar e sem compreender. Vivia como vivem os animais, como vivemos todos, cumprindo todas as funções da existência, observando e acreditando ver, acreditando saber, acreditando conhecer o que nos cerca, quando, um dia, me dei conta de que tudo é falso." (Maupassant, 2009, p. 465)

\section{Introdução}

O que é a psicanálise? Um método terapêutico dentro da psicologia, uma ciência, um conhecimento, uma ética ou uma hermenêutica? Não há como negar a articulação entre a Psicanálise e a Psicologia. Apesar de possuírem visões distintas do homem, do seu sofrimento e do seu tratamento, a presença da Psicanálise como uma das linhas psicoterápicas, debatida e transmitida ao aluno de Psicologia, permite ao mesmo um conhecimento único sobre a dinâmica psíquica presente em seus adoecimentos, seu sofrimento e na relação que esse possui com seu corpo.

Essa articulação, porém, não é fácil. Esse artigo tem como objetivo discutir sobre a atuação do profissional de Psicologia que elege a psicanálise como direção de trabalho e se situa para além do consultório, mais especificamente, em uma Unidade de Tratamento Intensivo (UTI) de um hospital, transmitindo e discutindo a experiência profissional de quem trabalha a partir desse campo de interseções e pesquisa.
A teoria psicanalítica nasceu da clínica com a qual sempre teve uma relação bastante peculiar. Jacques Lacan, em seu retorno a Freud, destaca a psicanálise enquanto uma práxis. Isto é, para ele, o saber fundado por Sigmund Freud, no século XIX, é fruto de uma constante inteiração entre a teoria e a prática. Dizendo de outra forma, a clínica psicanalítica criou e foi criada pela teoria que a fundamenta. Afinal, foi Anna O, paciente de Freud, a primeira a perceber "a cura pela fala" e foi Emmy Von $\mathrm{N}$ que pediu ao mesmo que a deixasse falar o que lhe viesse à cabeça, fundando, com isso, a única regra da psicanálise - a associação livre por parte do paciente e a atenção flutuante por parte do analista.

Freud, porém, antes de ser analista, era médico e teve que abrir seus ouvidos para uma outra escuta para que a psicanálise pudesse surgir. Assim, medicina e psicanálise demarcam campos de atuação profissional que se esbarraram e se esbarram até hoje, seja através do uso de termos em comuns como paciente, tratamento e diagnóstico, dentre outros, seja através da coabitação em um mesmo espaço de trabalho.

A comunicação entre os saberes da psicanálise e da medicina é prejudicada pelo desconhecimento prévio tanto dos limites de cada ciência quanto dos campos de interseção entre elas. O diálogo entre elas possibilita a delimitação do campo de atuação e de saber de cada área, além de poder proporcionar progresso não só para elas, mas, principalmente, para os sujeitos que se colocam em situação de sofrimento diante das duas disciplinas. É interessante notar que a dor com sede no corpo traz o paciente ao hospital, pois o corpo aparece 
para falar e revelar algo que não é dito. Cabe, então, aos profissionais ali presentes, escutar a queixa do paciente que pode ultrapassar o âmbito do corpo físico que ali se apresenta. Isto não implica uma exclusão da doença do discurso médico, mas sim a consideração de outra escuta, mais apurada, que, aliás, é própria da atividade clínica, desde seus primórdios, com Hipócrates (Alberti, Erlich, Mocarzel, Monteiro, Prata, \& Reis, 2008). Marie-José DelVolgo, médica fisiologista em um hospital francês, orientada pela proposta psicanalítica, constata:

A clínica, desprezada até pouco tempo, merece reencontrar um lugar de primeira ordem tanto em psicanálise como em medicina e a chance de um retorno da clínica em medicina se encontra na psicanálise. [...] É essencialmente uma questão de restabelecer as prerrogativas da clínica, uma clínica renovada pelo método psicanalítico, uma clínica do caso a caso (Volgo, 2003, pp. 26-27, citado por Pinto, 2012, pp. 412-413).

É da tensão entre a singularidade do caso e a generalidade da teoria que a clínica avança. A clínica deixa aberta a porta para a experiência ou para que o saber do médico se apague diante do leito do paciente, como diria Corvirsart (citado por Foucault, 2008).

Com relação ao presente trabalho, este configura-se a partir da experiência profissional dos autores. O estágio de um dos autores em um hospital público durante o ano de 2011, como pré-requisito para a obtenção do título de Especialista em Psicologia Hospitalar e da outra autora no Internato da faculdade de Medicina da Universidade Federal de Juiz de Fora. Vale ressaltar ainda que a confecção deste estudo coincide com a formação em Psicanálise dos autores que, como sugere Freud (1996a/1915), deve acontecer em tripé que se constitui da análise pessoal, da supervisão clínica e do estudo teórico.

Dessa forma, este estudo se engendrou por meio da práxis da psicanálise, levando em consideração que falar do analista em uma UTI só se faz possível através do que fundou e continua a trazer frescor para a teoria psicanalítica - sua clínica sustentada em uma escuta singular e nas invenções no caso a caso. Por isso, nossas considerações acerca das peculiaridades da escuta analítica na UTI são inspiradas pelas recomendações freudianas de que o analista não se furtasse aos novos desafios e campos de atuação que a cultura e o discurso da ciência trariam à clínica psicanalítica. Além disso, a crescente presença desse profissional nas equipes interprofissionais (Peduzzi, Normam, Germani, Silva, \& Souza, 2013) aponta para um campo de trabalho e pesquisa que tem se mostrado consistente e frutífero. Haja vista outros trabalhos como Alberti (2000), Belaga (2003), Rinaldi (2002), Moretto (2005), Americano, \& Bastos (2011), Gonçalves (2012), Tardivo (2014), que apontam todos para as possibilidades e limites de se levar a escuta analítica para o âmbito hospitalar sem que se abra mão da ética da psicanálise - ética da verdade do sujeito.

A UTI caracteriza-se por ser um espaço frio, silencioso e, ao mesmo tempo, ensurdecedor pelos bipes dos aparelhos. Neste cenário transitam médicos, enfermeiros, fisioterapeutas e, finalmente, corpos feridos, e estáticos em macas, que demandam respostas curativas, imediatas e urgentes. É nessa cena que, por vezes, um outro ator não menos importante, mas frequentemente mal compreendido, marca presença - o psicanalista (Netto, 2009).

Discutir acerca da importância do analista no hospital e, mais precisamente, na UTI é uma postura no mínimo curiosa. Geralmente, o psicanalista é visto como o profissional solitário que, trancado em seu consultório e sentado por detrás de um divã, escuta e trabalha a subjetividade de alguém que demanda ajuda para seu sofrimento psíquico. Assim, tal caricatura, muitas vezes verossímil, traz consigo a seguinte pergunta - como articular duas realidades tão díspares? Ou, falando de outra forma, o que permite, autoriza e justifica a presença de um psicanalista na UTI? (Netto, 2009).

Como ressalta Soares (2000), não somos apenas um corpo orgânico. Somos seres alienados na linguagem, atravessados pela falta e, por isso, desejantes. Dessa forma, os pacientes na UTI, assim como aqueles que, angustiados, procuram o consultório do analista, possuem suas fantasias e expectativas que, naquele momento, recebem uma nova tonalidade. Atrelado a isso, há também os familiares que, por sua vez, trazem para a UTI suas angústias oriundas da ruptura abrupta da dinâmica familiar e de todos os conflitos psíquicos que ali se atualizam. Finalmente, não podemos nos esquecer de todos aqueles que trabalham neste local e que, de uma maneira ou de outra, deparam-se com aquilo que escapa, com aquela que nem em nosso inconsciente encontra-se representada e que, por isso, causa pavor e até evitase dizer o nome - a morte. 


\section{Coppus, Alinne Nogueira Silva; Netto, Marcus Vinícius Rezende Fagundes (2015). A InSERÇ̃̃o do PSicanalista EM UMa UTI.}

O trabalho no hospital evoca tanto a ideia quanto o manejo da fragilidade. Como afirma Oliveira (2012), não raro este é o lugar onde as notícias que não se quer ouvir são ditas e expostas, como o diagnóstico de uma temida doença, o fato da mesma ser tratável ou não, a morte de um ente, enfim momentos que proporcionam uma experiência única e individual de padecimento e, por vezes, de angústia atroz. Além disso, dentro de um hospital talvez a UTI seja o local onde mais podemos perceber que vida e morte habitam a mesma casa (Secchin, 2006). Freud (1920/1996b) já havia dito que as pulsões de vida e pulsão de morte encontram-se entrelaçadas no aparelho psíquico e aqui, isso também se apresenta. A UTI é um lugar onde os avanços médicos e tecnológicos apontam para todas as potencialidades humanas de lutar em prol da vida, mas, ao mesmo tempo, a eminência constante de morte nos mostra nossa castração e, por conseguinte, nossa tão negada incompletude e limitação. Assim, a UTI que, inicialmente, parece inóspita para o analista, revela-se como um lugar propício para a construção de uma cadeia de significantes que propicie o estabelecimento de novos significados, de novos investimentos que, por sua vez, apontem para saídas possíveis nesse contexto.

No entanto, escutar um sujeito que padece diante da morte - seja ele o paciente, os familiares ou os membros da equipe - tem suas particularidades no que tange o contexto da UTI. Por isso, faz-se necessário um discurso outro que, todavia, não é contrário ao discurso psicanalítico. Na verdade, esse deve ser tributário dos ensinamentos freudianos, pois só assim se é possível adequar a escuta e problematizar o setting analítico à realidade que nos é colocada pela UTI.

\section{A inserção do psicanalista no hospital: a ordem médica e o discurso da psicanálise}

Ao entrarmos em uma UTI de um hospital não há dúvidas de que estamos, a rigor, na casa do médico. É ali onde os maiores avanços técnico-científicos encontram-se encarnados em um verdadeiro maquinário que, junto aos leitos, fazem com que os corpos, na maioria das vezes estáticos e aparentemente sem vida, possam respirar, serem nutridos e terem o sangue filtrado.

O médico, como hoje é o psicólogo/psicanalista, também já foi apenas um convidado dentro do hospital, onde prestava seus serviços. Podemos perceber isso a partir das contribuições de Michel Foucault que, em suas obras A história da Loucura e o Nascimento da clínica, informa-nos, através de uma descrição precisa, sobre como esse processo se engendrou. Todavia, não vamos nos ater a esse tema que, por sua riqueza e complexidade histórica, merece um estudo a parte. Interessa-nos mais partir das articulações de Jean Clavreul sobre o conceito de Ordem Médica.

Clavreul (1983) ressalta que o discurso médico se coloca através da ordem médica e essa é um imperativo que não tem que ser defendido, não precisa ser demonstrado e não abre espaço para ser refutado. Assim, quanto ao discurso sobre a medicina, só nos resta apreender o insistente mal-estar dos autores que o apoiam ou o criticam já que não são suficientes para modificar ou desbancar a ordem médica.

A ordem médica é um imperativo que está presente em nossas vidas desde nosso nascimento até a nossa morte. Desde o pré-natal, dizendo se somos saudáveis, se somos menino ou menina, até a autópsia que esclarece a razão da morte. Mais do que a eficácia do saber médico, é a cientificidade da ordem médica que se impõe como lei que veta qualquer tipo de contestação a seu saber. Mesmo porque, a liberdade de se recusar o saber médico, encarnado em um diagnóstico ou tratamento, equipara-se à escolha pela morte que, por sua vez, é vista como loucura e esta também deve ser confiada ao médico para ser tratada. Então, "a ordem médica é mais poderosa que o mais poderoso ditado e, às vezes, tão cruel. Não se pode resistir a ela, porque não se tem nenhuma razão para lhe opor" (Clavreul, 1983, p. 47).

No entanto, é importante ressaltar que não é apenas o doente que é despossuído de sua relação com a doença, de seu sofrimento, ou seja, de sua posição subjetiva no processo de adoecimento. Clavreul (1983) deixa bem claro que o médico também o é. Na verdade, este é chamado a calar seus sentimentos e, como o doente, esvanece diante da doença. Dessa forma, o médico também se apaga diante de seu saber. É por isso que Lacan (apud Clavreul, 1983) informa não existir a relação médico-paciente e que esta seria substituída pela relação instituição de saúde e doença. A ordem médica, portanto, apaga a posição do doente no enunciado do seu próprio sofrimento, mas também apaga a do médico submetido a seu discurso.

Dessa forma, antes de atacarmos o discurso médico colocando-o em posição de inferioridade com relação a outros como, por exemplo, o discurso da psicanálise, devemos antes entender que fazer 
a experiência do discurso, é fazer a experiência do inconsciente, que é estruturado como uma linguagem, efeito do discurso. (Clavreul, 1983). Não é à toa que a partir de um momento particular do ensino de Lacan (1969-70/1992), podemos depreender que o discurso da psicanálise é subversivo justamente por não se pretender enquanto tal. Atrelado a isso, Lacan (1974/1993) também enfatiza que revolucionar é apenas voltar ao mesmo ponto, à eleição de um novo mestre e isso não tem nada de analítico!

Com isso, a experiência da psicanálise a partir do discurso médico não é um procedimento científico com o intuito de completá-lo, compensá-lo ou atacá-lo naquilo que se faz faltoso. Trata-se exatamente do contrário. A práxis do analista na equipe multiprofissional de um hospital não coincide com a do médico e a dos outros profissionais que lá se encontram. Ao analista não cabe tentar restituir a norma, a linha reta, o equilíbrio a partir do que falta no saber médico. Lacan (1969-1970/1992) vem nos trazer, a partir de sua leitura da obra freudiana, a especificidade da ética da psicanálise e é com seu ensino de Lacan que podemos entender que a busca de um homem total através de uma medicina holística não é possível.

Assim, junto à equipe, cabe ao analista escutar. Não que ele vá atender os membros da equipe. Não se trata disso! O analista está lá para que algo da experiência analítica, principalmente aquilo que concerne à dimensão do sujeito como barrado, efeito da castração simbólica, seja transmitido. Ora, contrariando o senso comum de que a UTI seria inóspita ao analista, um ambiente em que a possibilidade de morte - representante último da castração - coloca-se tão presente, $\mathrm{o}$ analista parece ter um campo bastante frutífero para sua atuação.

Além disso, mesmo que o hospital seja um reduto do saber médico, isso não impede que o psicanalista consiga ouvir a existência de um outro corpo, para além do orgânico, sobre os leitos que lá se encontram. As histéricas, já no século XIX, disseram que o corpo é o campo onde os conflitos inconscientes ganham materialidade e o desejo deturpa as funções ditas naturais. Atravessado pela linguagem, ou seja, marcado pelo significante, o corpo serve de continente para o gozo, perdendo sua dimensão natural. Desse modo, é justamente quando o médico se depara com esse corpo estranho ao seu saber que coloca em cena a subjetividade daquele que sofre, que a práxis da psicanálise torna-se uma possibilidade na cena hospitalar. No entanto, quando falamos da entrada do psicanalista no hospital e, consequentemente, em uma UTI, temos que entender que essa entrada, ou seja, sua presença, não garante sua inserção.

Em sua experiência com outros profissionais de Psicologia do Hospital das Clínicas de São Paulo, Moretto (2006) diz que o que mais seus colegas se queixam é de não terem um lugar efetivo na equipe de saúde. Entretanto, fato é que o médico - diante de um corpo que para ele é estranho - costuma fazer uma demanda (de saber) ao analista. Ora, se existe uma demanda por parte do profissional de saúde, porque os analistas reclamam de não serem escutados, de não terem suas opiniões levadas em consideração e, com isso, de não terem um lugar na equipe? Bom, de saída uma importante distinção deve ser feita: entrar em uma equipe de saúde de um hospital, CAPS ou PSF, não significa estar inserido na mesma.

A entrada de um psicólogo/psicanalista em um hospital tem a ver com um contrato. Falando de outro modo, a entrada se dá em uma determinada data, a seu trabalho é atribuído um valor e suas funções, como psicólogo, são previstas por esse documento. Relaciona-se a inserção, por outro lado, ao ato, à criação de um lugar psíquico junto à equipe, da qual o analista faz parte. $\mathrm{Ou}$ seja, estar dentro fisicamente, não quer dizer, em absoluto, estar inserido psiquicamente e, portanto, a inserção do analista na equipe ultrapassa a abertura de vagas no quadro de funcionários de um hospital (Moretto, 2006).

Mas como o analista pode se inserir em uma equipe? Como possibilitar e sustentar esse lugar psíquico? Segundo Moretto (2006), a maneira como o analista acolhe as demandas que lhe são feitas pela equipe, podendo ser esse pedido a abertura de um espaço transdisciplinar na equipe ou não, aponta para uma via de inserção desse profissional. Assim, para a autora, o processo de inserção do analista está relacionado ao tipo de demanda que a equipe lhe dirige e como a mesma é escutada e acolhida.

Todavia, quando falamos em demanda, temos que ter clara a distinção entre uma demanda de trabalho e uma demanda de presença. A seguir, em um esquema proposto por Moretto (2006), percebe-se como duas equipes hipotéticas se posicionariam diante da emergência da subjetividade e, a partir daí, com que propósito fariam um pedido de encaminhamento ao psicanalista que, em uma equipe de saúde, é, geralmente, encarnado pelo psicólogo (Figura 1). 


\section{Coppus, Alinne Nogueira Silva; Netto, Marcus Vinícius Rezende Fagundes (2015).}

A InSERÇão do PSicanalista EM UMa UTI.

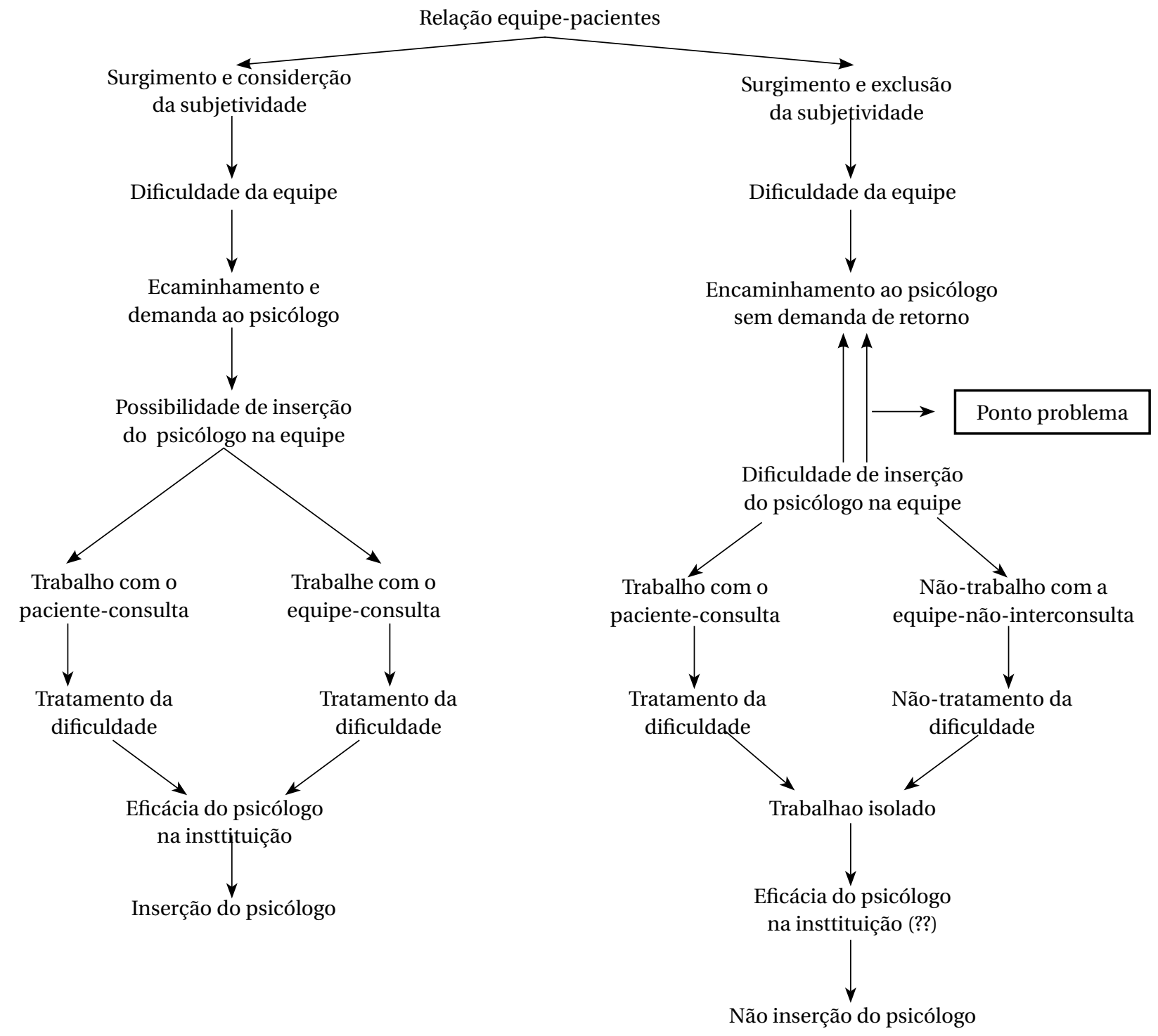

Fonte: Moretto, 2006.

Figura 1. Inserção e entrada.

A primeira equipe, da esquerda para a direita, demanda trabalho do analista. É aquela que, diante da subjetividade com a qual não sabe lidar, faz um encaminhamento. No entanto, as coisas não param por aí. Há ainda um trabalho posterior-a interconsulta ou, como tambémé conhecida, a devolutiva. Assim, neste tipo de equipe, existe a consideração da subjetividade, já que, diante da mesma, ocorre um encaminhamento e, posteriormente, um pedido de interconsulta. Ou seja, essa equipe faz uma demanda de saber ao analista sobre a subjetividade do paciente ou até da própria equipe com a qual não sabe lidar.

Por outro lado, há ainda, no esquema, a equipe que, frente ao surgimento da subjetividade do paciente, a exclui, não permitindo que a mesma seja uma via de trabalho e crescimento para a própria equipe. Ou seja, há o encaminhamento ao analista sem que os profissionais efetivamente queiram saber o que se passa ali. O que se quer é apenas a presença do analista para resolver (leia-se eliminar) aquilo que é estranho à equipe. Não há espaço para o trabalho de interconsulta e, portanto, não há demanda de saber acerca da subjetividade dos pacientes. Dessa forma, enquanto no primeiro tipo de equipe há efetivamente um trabalho em equipe, no segundo o que existe é um trabalho individual por parte do analista. Dizendo de outro modo, na primeira equipe o analista está inserido, na segunda ele apenas entrou. 
Percebemos então que o fato de uma equipe fazer um encaminhamento ao psicanalista não significa que ele esteja inserido na mesma. Por isso, devemos diferenciar os encaminhamentos e as demandas que são feitas. Assim, um alto número de encaminhamentos não corresponde, necessariamente, a demandas efetivas de intervenção do analista no campo institucional. $\mathrm{O}$ alto número de encaminhamentos, portanto, é um indicador importante de que a equipe tem dificuldades em lidar com a subjetividade, mas isso não quer dizer que essa equipe queira tratar dessa dificuldade (Moretto, 2006). Cabe ao psicanalista ouvir e tentar fazer com que os próprios profissionais de saúde escutem o que, a princípio, encontra-se velado nas suas falas, mas que, a partir do posicionamento dos próprios profissionais de saúde frente os impasses que o paciente coloca aos mesmos, aparece na cena clínica.

A partir de nossa experiência destacamos que a frustração de um médico diante de um paciente que não adere ao tratamento, a irritação de um técnico de enfermagem diante de um paciente que não cessa em lhe pedir água, mesmo não tendo sede e o apaixonamento de um paciente por seu fisioterapeuta e uma enigmática melhora em seu quadro a partir disso, são apenas algumas das inúmeras situações que apontam para os limites de uma saber diante de um corpo que goza e, por isso, nem sempre obedece as leis do saber médico e técnico.

Por conseguinte, como encaminhamentos não equivalem diretamente à demanda de saber, o psicólogo não pode se valer da estatística de encaminhamentos a ele dirigidos para mensurar o valor institucional de seu trabalho. Dessa forma, afirmamos que a inserção do psicólogo/psicanalista na cena médica implica um ato, que depende do próprio profissional e também da equipe em que está inserida. Freud e Lacan ensinam aos psicanalistas que o ato diz de uma mudança de lugar e sobre ele só se sabe a posteriori. Tomamos como exemplo o ato falho, que aponta a possibilidade de uma mudança de lugar do sujeito naquilo que ele fala e consequentemente na surpresa de sua escuta. O que se vê aí não é mais o sujeito da consciência, do cogito cartesiano e, com isso, certo de sua inteireza. $\mathrm{O}$ ato analítico traz à tona o estranho que nos habita, o sujeito dividido, o sujeito do inconsciente que possibilita que novos arranjos de dêem.

A partir de dois recortes clínicos, problematizamos a diferença entre a entrada e a inserção do psicanalista na equipe multiprofissional de saúde.

\section{O poder de um medicamento e uma provável psicose}

\section{Relato 1}

Sr L estava na UTI há uma semana e, de acordo com a equipe, o paciente estava muito agitado $e$, por isso, foi feito o encaminhamento ao serviço de Psicologia. No atendimento, o paciente trazia uma extrema dificuldade para dormir devido à claridade e ao barulho dos bipes dos aparelhos. Atrelado a isso, a filha diz que o pai tomava o mesmo remédio para dormir há 15 anos. "Ele sempre foi muito ansioso, esse medicamento é o único que o faz dormir. Tem como você perguntar para o médico se ele está tomando a medicação correta aqui?". Diante disso, converso com o médico que me diz que o paciente estava sim tomando um ansiolítico que tinha a mesma fórmula daquele do qual eu falava. Pergunto então à enfermeira se Sr L sabia o nome do medicamento que estava tomando e esta me informa que sim. "Ele perguntou o nome do ansiolítico e dissemos a ele!". Direciono-me novamente ao médico e digo a ele da importância que o paciente tomasse exatamente a mesma medicação que vinha tomando há quinze anos, uma vez que já estava destituído subjetivamente de muitas coisas. Estava ali sem sua esposa, sem seus filhos, não podia fazer as coisas que gostava em seu cotidiano e, por isso, seria interessante que mantivéssemos a medicação com a qual ele estava acostumado. O médico vai até ao leito e pede à família que traga o remédio. Naquele dia, Sr L conseguiu dormir.

\section{Relato 2}

N.D tinha sido levada para a Unidade Coronariana devido a uma tentativa de suicídio. No prontuário o psiquiatra, que não fazia parte do corpo clínico do hospital, mas atendia por meio de encaminhamentos, havia diagnosticado a paciente com Transtorno de depressão e ansiedade, mas colocou uma interrogação diante do mesmo e pede o parecer do serviço de Psicologia.

Quando converso com ND ela diz que tinha acabado de se formar, estava começando uma pósgraduação em sua área e tinha saído de casa para morar sozinha. No entanto, mesmo com tantas conquistas não estava se sentindo bem. Tinha muito medo de morrer e relatava um grande receio com relação a seus vizinhos. Pergunto quando isso havia começado e ND diz que um dia as crianças de sua rua brincavam de futebol fazendo a porta de sua casa 


\section{Coppus, Alinne Nogueira Silva; Netto, Marcus Vinícius Rezende Fagundes (2015). A InSERÇão do PSicanalista EM UMa UTI.}

de gol. O barulho da batida da bola em sua porta a incomodava muito e ND então abriu a porta, pegou a bola das crianças e disse que não a devolveria mais. Assim, o pai e a mãe de uma das crianças foram a até sua casa e, de forma muito grosseira, pediram a bola de volta.

A partir desse dia, ND desenvolveu um grande medo com relação a seus vizinhos e achava, inclusive, que eles poderiam matá-la. Assim, ND decide ir passar uns tempos com a irmã que morava no terceiro andar de um prédio. No dia anterior a sua internação na UC, ND estava em casa sozinha quando ouviu batidas na porta. "Eram eles querendo me matar. Tenho certeza. Por isso, pulei pela janela. Eu não queria morrer".

Mesmo sabendo que com base em um atendimento não seria possível apostar em um diagnóstico estrutural de psicose, chamava bastante atenção o lugar que ND ocupava diante do Outro que, em seu discurso, perseguialhe e tentava matá-la fazendo-a, dessa forma, objeto de um gozo mortífero. Atrelado a isso, enquanto conversava comigo estava preocupada não só mais com os vizinhos, mas também com uma das técnicas de enfermagem que, segundo ela, poderia contar a seus vizinhos que ela estava ali.

Além disso, o aparente delírio começara em um momento em que ND havia sido convocada a ocupar novos lugares em sua vida. Tinha se formado, entrado no mercado de trabalho e passara a morar sozinha e todas essas mudanças pareciam-lhe insuportável. Com isso, resolvi entrar em contato com o psiquiatra para discutirmos o diagnóstico. Entretanto, ND teve alta antes que eu conseguisse falar com o médico mesmo depois de inúmeras tentativas.

A partir do que foi discutido até o momento, podemos perceber que no primeiro relato existe efetivamente um lugar para o analista na equipe. Houve um pedido de atendimento por parte da equipe diante do fato do paciente não conseguir dormir mesmo estando medicado para tal e, na interconsulta, a equipe se mobilizou para que o paciente voltasse a tomar o medicamento com o qual estava acostumado. Ou seja, no caso do $\mathrm{Sr} \mathrm{L}$ a equipe não só faz o encaminhamento diante do surgimento da subjetividade, mas esse encaminhamento é, na verdade, uma demanda de saber dirigida ao analista com relação à subjetividade.

No caso de ND, todavia, há o encaminhamento, mas o pedido se resume a uma demanda de resolução do que é visto como um problema sem um envolvimento da equipe na solução/problematização do mesmo. $\mathrm{O}$ médico - que não fazia parte do corpo clínico do hospital - não dava lugar à atuação do analista na equipe. Para ele, o psicanalista estava dentro da equipe, mas não estava, necessariamente, inserido na mesma. É claro que nesse caso, em específico, o médico não fazia parte da equipe e, por isso, a chance de que ele desse, efetivamente, lugar para o trabalho analítico, era mínima. No entanto, é inegável que o médico sabia da existência do serviço de Psicologia, uma vez que o encaminhamento foi feito, mas isso não foi $\theta$ suficiente para que esse fizesse uma demanda de saber em relação ao mesmo.

Ora, além de apontarem para a diferença existente entre entrada e inserção do psicanalista em uma equipe de saúde, os casos acima relatados também nos dizem da singularidade da clínica psicanalítica em comparação à clínica médica. O lugar que um medicamento, uma doença, seu corpo e até o próprio médico ocupam para o paciente é uma maneira de sabermos um pouco mais sobre ele, seu posicionamento nas suas relações e as maneiras com que lida com as dificuldades. Além disso, a diferença diagnóstica estrutural implica o dever ético de intervenções diferenciadas por parte da equipe, evitando, com isso, efeitos desastrosos para o paciente e para a equipe, caso isso não seja levado em consideração.

\section{A especificidade de uma clínica}

$\mathrm{Na}$ maioria das vezes, de forma equivocada, fala-se de uma diferença entre a clínica médica e a psicológica/psicanalítica pelo fato de as mesmas não se dirigirem aos mesmos tipos de doentes. Isso é pensado a fim de decidir uma orientação terapêutica mais efetiva. Logicamente, esse posicionamento frente ao sofrimento humano reduz o problema àquele clássico e rotineiro em medicina que é o da determinação de uma melhor especialidade para o tratamento de um paciente (Clavreul, 1983). Assim, para cuidar de um distúrbio de visão vai-se ao oftalmologista, para tratar de uma cardiopatia procura-se um cardiologista e para resolver questões emocionais deve-se conversar com um psicólogo.

No entanto, essa situação de subordinação com relação ao saber médico não é adequada à prática psicanalítica. Não por uma questão narcísica de considerarmos o tratamento psicanalítico mais eficaz do que aquele promovido pelo médico. Isso pode ou não ser verdade. Depende do caso. A questão que se coloca é 
que a psicanálise não deve ser subordinada ao saber médico, pois aquela instaura um outro discurso, uma outra clínica (Clavreul, 1983).

Dessa forma, muitas vezes o psicólogo pode se render ao establishment, tentando se adequar ao discurso médico. Com isso, toma a demanda médica de maneira imperativa e responde à mesma tentando: fazer com que um paciente pare de chorar, reverter um quadro de não adesão ao tratamento ou, até mesmo, controlar um familiar nervoso com a piora de um ente querido. Essa postura, sem sombra de dúvidas, pode trazer benefícios imediatos, mas esses apenas camuflam o fato de que o que se está fazendo é tudo, menos psicanálise (Clavreul, 1983).

Afinal, é pela própria psicanálise que o conceito de psicoterapia foi subvertido. A hipnose e a sugestão, que encantaram Freud no início de sua clínica, iam ao encontro do discurso médico. O médico mantinha, através desse método, o controle sobre as idéias-julgadas por ele adequadas - para que o paciente pudesse se livrar de sua neurose. É fato que alguns analistas só fizeram retornar a essa posição mesmo que Freud a tenha abandonado ainda em seu tratamento das histéricas.-(Clavreul, 1983).

Todavia, temos que ter em mente que a teoria psicanalítica não é um corpo doutrinal que se deve ensinar ou comprovar a todo instante nas salas de graduação em Psicologia, no divã dos consultórios ou até mesmo dentro das instituições como o hospital e mais especificamente os leitos da UTI. A clínica psicanalítica aposta na manifestação do inconsciente através da palavra, do sofrimento do corpo, do que não se explica, do que nos causa. Tais manifestações apontam para uma presença que tem efeitos na maneira como o sujeito se coloca na vida, como se relaciona com seu corpo, com seu sofrimento e em suas relações. Efeitos que irão se fazer presentes também ali, no hospital.

A teoria psicanalítica é, a rigor, um conjunto de referências que permitem ao analista ouvir seu paciente de maneira peculiar. $O$ paciente sofre por não poder dizer o que tem a dizer, por não representar suas pulsões a não ser pela estranha forma do sintoma. Por isso, a interpretação do analista não coincide com a do médico que se baseia na teoria para dizer exatamente qual é o mal do paciente e o que ele deve fazer a partir de então. Ao analista, cabe recolher os efeitos de sujeito que o paciente deixa transparecer em sua fala através das formações do inconsciente como os chistes, os atos falhos, os sonhos e os sintomas, trabalhando sobre esse material a fim de que o paciente se escute.

Além disso, no caso do adoecimento psíquico, a medicina sempre fez um diagnóstico de eliminação. Nos tempos em que Freud foi aluno de Charcot, a histeria cumpria essa função, no que concerniam as disfunções neurológicas. Ou seja, naqueles quadros em que a etiologia orgânica não era clara, o diagnóstico era de histeria. Hoje poderíamos arriscar se o tão propalado Transtorno Bipolar de Humor e o Transtorno de Déficit de Atenção e Hiperatividade não cumprem essa mesma função (Clavreul, 1983).

Com isso, Clavreul (1983) ressalta que as doenças mentais, pelo menos em sua maioria, não têm ainda causa localizável no discurso médico e, dessa forma, a medicina as rejeita para o registro de um imaginário que não é nada mais do que a pura inexistência - o absolutamente nada. Por isso, a resposta "não é nada, é emocional” à histérica, significa a inexistência desses sintomas para o discurso médico. Retomemos Freud (1909/1996c) que nos indicará o porquê deste posicionamento da Ordem médica diante daquilo que escapa a seu discurso.

Com o rótulo de histeria pouco se altera, portanto, a situação do doente, enquanto que para o médico tudo se modifica. Pode-se observar que este se comporta para com o histérico de modo completamente diverso que para com o que sofre de uma doença orgânica. Nega-se conceder ao primeiro o mesmo interesse que dá ao segundo, pois não obstante as aparências, o mal daquele é muito menos grave. Em face das particularidades dos fenômenos, todo seu saber e todo seu preparo deixam-no desamparado. Não pode compreender a histeria, diante da qual se sente um leigo, posição nada agradável a quem tenha em alta estima o próprio saber. Os histéricos ficam, assim, privados de sua simpatia. Ele os considera como transgressores de sua ciência, tal como os crentes consideram os hereges: julga-os capazes de todo o mal, acusa-os de exagero e de simulação, e pune-os com lhes retirar seu interesse (Freud, 1909/1996c).

Quanto ao psicanalista, este não toma o diagnóstico clínico de uma dor, de uma doença ou até mesmo o próprio diagnóstico estrutural das neuroses, das psicoses e das perversões a partir da ausência de uma causa orgânica para aquele sintoma ou fenômeno apresentado pelo paciente. O diagnóstico é feito a partir do posicionamento do sujeito frente à castração e, consequentemente, ao Outro, o que gera 


\section{Coppus, Alinne Nogueira Silva; Netto, Marcus Vinícius Rezende Fagundes (2015). A InSERÇ̃̃o do PSicanalista EM UMa UTI.}

alterações na maneira como o sujeito está inserido na linguagem. Além disso, é preciso lembrarmos de algo muito importante e que marca a especificidade da clínica psicanalítica: o sintoma que norteia o diagnóstico médico não tem o mesmo lugar do sintoma para a psicanálise, e mais, um mesmo sintoma pode ter funções diferentes para sujeitos diferentes.

Para a medicina, o sintoma é um signo. Ele representa alguma coisa para o médico. Logo, se o paciente apresenta febre isso pode indicar, para o médico, que o paciente, provavelmente, tem algum tipo de infecção e que deve, por sua vez, ser eliminada. Para o analista, no entanto, o sintoma é fruto de um conflito psíquico, é uma formação do inconsciente e, como tal, é um significante que pode nos dar notícias sobre o posicionamento daquele sujeito diante do Outro da linguagem. Com isso, Lacan (1955-56/1997) nos adverte para não nos apegarmos à fenomenologia dos distúrbios como critério para desvendar a estrutura. Eles podem ser enganosos.

Essa diferença entre o diagnóstico médico e aquele feito pelo psicanalista pode ser ilustrada pelo segundo relato de caso apresentado acima. O psiquiatra, que chegara ao diagnóstico de Transtorno de depressão e ansiedade para ND, o fez com base no fato de que a paciente tentara suicídio, apresentava rebaixamento de humor e estava bastante irrequieta durante a anamnese. Ou seja, o médico valeu-se dos sintomas que aqui têm valor de signo para realizar seu diagnóstico que, segundo suas referências como DSM-IV e o CID 10 estava, possivelmente, correto. Ou, ao menos, estava de acordo com seu discurso.

Por outro lado, o diagnóstico deste mesmo caso, para a psicanálise, aponta para outra direção já que, para Lacan (1955-56/1988), o que possibilita chegar a uma conclusão estrutural é o posicionamento do sujeito diante da castração, o que gera diferenças em sua inserção na linguagem. Assim, o diagnóstico em psicanálise não é decorrente apenas dos fenômenos que se fizeram presentes durante as entrevistas preliminares, mas, principalmente, ao posicionamento do ND diante do Outro, e de seu especial modo de crença que dizia de uma perseguição dos vizinhos que queriam matá-la.

No entanto, ainda em relação ao diagnóstico, é importante enfatizar que o mesmo deve ser feito, pelo psicanalista, na transferência e, de preferência, com tempo. É através do vínculo afetivo existente entre o paciente e o analista que o mesmo, investido como objeto fantasmático, percebe em que lugar o sujeito, em sua série de clichês estereotípicos, o coloca para poder, dessa maneira, fazer o diagnóstico estrutural.

No caso de ND, foi feito apenas um atendimento e, por isso, não foi possível saber se ela me colocaria no lugar em que colocara os vizinhos, mas fato é que já o fizera com uma das técnicas de enfermagem que, para ela, poderia passar informações suas para os seus perseguidores.

Com relação ao médico, não há dúvidas de que esse também é alvo de transferência. No entanto, muitas vezes não está avisado disso e vale-se da mesma para governar o paciente, dizendo do que o mesmo sofre e o que poderá fazer para se sentir melhor. Portanto, não cabe a"ninguém duvidar de que ele sabe - melhor que qualquer outro - qual é o bem de seu doente" (Clavreul, 1983, p. 184).

Atrelado a isso, não podemos ignorar o fato de que, para o médico, a cura da doença depende da observância dos ritos médicos e dos imperativos impostos pela Ordem médica e não dos sentimentos conscientes ou inconscientes que o doente possa, por ventura, ter pelo médico que lhe trata (Clavreul, 1983).

A "cura" para a psicanálise nem sempre está em consonância à cura médica. "Curar" em psicanálise não se relaciona à supressão dos sintomas, mas diz, principalmente, de uma mudança de posição subjetiva. O sujeito em análise é aquele que começa a se implicar com seu processo de adoecimento e, a partir disso, tenta responder a mesma pergunta que Freud (1905/1996d) fez a Dora a respeito de sua responsabilidade na tragédia da qual se queixava. Ou seja, a cura em psicanálise refere-se, como nos indica Freud (1917/1996e), a tornar um sofrimento neurótico em um sofrimento comum.

Assim, o psicólogo/psicanalista que atua na cena hospitalar não deve tentar se adequar ao modelo médico para poder "trabalhar em equipe" e atingir a meta de um discurso diferente do seu. Caso o faça, sua práxis se desviará radicalmente daquilo que constituiu a originalidade e a especificidade da clínica psicanalítica. Vale ressaltar que o trabalho do psicanalista no hospital, caso efetivamente consiga sua inserção, permite tratar um sujeito que há muito não pode ficar restrito à divisão cartesiana entre mente e corpo. O inconsciente demonstra que o corpo não é apenas orgânico e sim que ele é afetado pelo que se diz dele, pela maneira com que é representado, pelos afetos do homem (Miller, 2014). É com esse corpo que ele adoece e é desse corpo, que muitas vezes, ele padece. 


\section{Considerações finais}

A atuação de um psicólogo/psicanalista na UTI de um hospital, se comparada ao que se faz em um consultório particular tem, obviamente, suas especificidades e foram essas que sublinhou-se nesse trabalho. Todavia é importante lembrar que não se faz psicanálise aplicada sem psicanálise pura. Ou seja, o trabalho do analista, onde quer que ele ocorra, deve ser sustentado por uma formação rigorosa que, como vimos, inclui sua própria análise pessoal, a supervisão dos casos que atende e sua formação teórica. Seguindo a recomendação freudiana de que em psicanálise clínica e pesquisa coincidem, acreditamos então que no âmbito da formação teórica poderíamos incluir a produção teórica a partir da clínica. O diálogo entre Psicologia e Psicanálise, assim como entre psicanálise

\section{Referências}

Alberti, S. (2000). Psicanálise: a última flor da medicina. In S. Albert, L. Elia (Orgs.), Clínica e pesquisa em psicanálise (pp. 37-55). Rio de Janeiro, RJ: Rios Ambiciosos.

Alberti, S., Erlich, H., Mocarzel P., Monteiro, P., Prata, D., \& Reis, L. E. G. (2008). Encaminhamentos e dispersão: questões para a psicanálise no hospital. Estudos e Pesquisas em Psicologia, 8(1): 42-57. Recuperado de http://www.revispsi.uerj.br/ v8n1/artigos/pdf/v8nla05.pdf

Americano, B., \& Bastos, F. (2011) A psicanálise no hospital universitário. In H. Caldas, \& S. Altoé. Psicanálise, universidade e sociedade (pp. 355-361). Rio de Janeiro, RJ: Cia de Freud.

Belaga, G. A. (2003). O psicanalista aplicado ao hospital. In H, Caldas (Org). Os usos da psicanálise: primeiro encontro americano do campo freudiano (pp. 9-18). Rio de Janeiro, RJ: Contra Capa.

Clavreul, J. (1983). A ordem médica: poder e impotência do discurso médico. São Paulo, SP: Brasiliense.

Foucault, M. (2008). O nascimento da clínica. Rio de Janeiro, RJ: Forense Universitária. (Obra original publicada em 1963).

Freud, S. (1996b). Além do princípio do prazer. In S. Freud. Edição standard brasileira das obras psicológicas completas de Sigmund Freud. (James Stra- e hospital tem ainda um caminha a trilhar. Mais do que apontar as diferenças e as impossibilidades entre esses campos, vale partilhar a experiência de quem sustenta um lugar êxtimo ${ }^{1}$ e solitário, capaz de fazer surgir um modo diferente de atuar e produzir efeitos de sujeito.

Afinal, em um contexto regido por um discurso que não é o seu, mas que, paradoxalmente, nele se encontra inserido, o analista poderá produzir na equipe uma demanda de saber possibilitando então sua inserção na equipe via transferência de trabalho.

Com isso, faz-se necessário a produção de outros estudos que possam trazer contribuições acerca do tema aqui abordado, sem deixar de colocar em evidência a originalidade da psicanálise e a descoberta freudiana de, a partir do caso a caso, tangenciar o universal.

chey, trad., vol. XVIII, pp. 17-75). Rio de Janeiro, RJ: Imago. (Obra original publicada em 1920)

Freud, S. (1996c). Cinco lições de psicanálise. In S. Freud. Edição standard brasileira das obras psicológicas completas de Sigmund Freud (J. Strachey, trad.,vol. XI, pp. 16-55). Rio de Janeiro, RJ: Imago. (Obra original publicada em 1909)

Freud, S. (1996d). Fragmento da análise de um caso de histeria. In S. Freud. Edição standard brasileira das obras psicológicas completas de Sigmund Freud. (J. Strachey, trad., vol. VII, pp. 19-116). Rio de Janeiro, RJ: Imago. (Obra original publicada em 1905)

Freud, S. (1996a). O inconsciente. In S. Freud. Edição standard brasileira das obras psicológicas completas de Sigmund Freud. (J. Strachey, trad., vol. XIV, pp. 165-222). Rio de Janeiro, RJ: Imago. (Obra original publicada em 1915)

Freud, S. (1996e). Luto e melancolia In S. Freud. Edição standard brasileira das obras psicológicas completas de Sigmund Freud. (J. Strachey, trad., vol. XIV, pp. 245-263). Rio de Janeiro, RJ: Imago. (Obra original publicada em 1917)

Gonçalves, A. D. (2012). De UTI a UCI: relato de uma experiência com a psicanálise. Revista Psicologia, Diversidade e Saúde, 1(1), 129-139. doi: 10.17267/2317-3394rpds.vli1.52

1. Termo utilizado por Lacan para designar a aproximação entre o externo e o íntimo a partir de uma retomada ao texto O estranho de Sigmund Freud em que o autor nos diz que a sensação de estranheza é proveniente de algo que nos é, também, íntimo. 
Lacan, J. (1988). As psicoses. In J. Lacan, O seminário (livro 3). Rio de Janeiro, RJ: Jorge Zahar. (Obra original publicada em 1955-56)

Lacan, J. (1997). A ética da psicanálise. In J. Lacan, $O$ seminário (livro 7). Rio de Janeiro, RJ: Jorge Zahar. (Obra original publicada em 1955-56)

Lacan, J. (1992). O avesso da psicanálise. In J. Lacan, O seminário (livro 17). Rio de Janeiro, RJ: Jorge Zahar. (Obra original publicada em 1969-70)

Lacan, J. (1993). Televisão. Rio de Janeiro, RJ: Jorge Zahar. (Obra original publicada em 1974).

Maupassant, G. (2009). O medo. In 125 contos de Guy de Maupassant. São Paulo, SP: Companhia das Letras, p. 465-472.

Miller, J.-A. (2014). L'inconscient et le corps parlant. In Conferência no 100. Congresso da AMP. Paris, França. Recuperado de http//www.wapol.org/ Template.asp

Moretto, L. M. (2006). O psicanalista num programa de transplante de figado: a experiência do 'outro em si' (Tese de Doutorado). Instituto de Psicologia, Universidade de São Paulo, São Paulo.

Moretto, L. (2005). O que pode um analista no hospital? São Paulo, SP: Caso do Psicólogo.

Netto, M. V. R. F. (2009). O lugar do analista no hospital (Monografia). Pós-graduação em Psicanálise Subjetividade e Cultura, Universidade Federal de Juiz de Fora, Juiz de Fora.

Oliveira, A. T. (2012). As emoções do profissional intensivista no manejo com a morte (Monografia). Pós-graduação em Políticas e Pesquisa em Saúde Coletiva. Universidade Federal de Juiz de Fora, Juiz de Fora.

Peduzzi, M., Norman, I. J., Germani, A. C. C. G., Silva, J. A. M., \& Souza, G. C. (2013). Educacao interprofissional: formacao de profissionais de saude para o trabalho em equipe com foco nos usuarios. Revista da Escola de Enfermagem da USP, 47(4), 977-983. doi: 10.1590/S0080-623420130000400029

Pinto, T. (2012). Crítica do empirismo aplicado à psicopatologia clínica: da esterilidade do DSM a uma saída pela psicanálise. Ágora: Estudos em Teoria Psicanalítica, 15(n.esp.), 405-420. doi: 10.1590/S1516-14982012000300004

Rinaldi, D. (2002). O desejo do psicanalista no campo da saúde mental: problemas e impasses da inserção da psicanálise em um hospital universitário. In D. Rinadi, \& M. A. C. Jorge, Saber, verdade e gozo: leituras do seminário, livro 17 de Jaques Lacan (pp. 53-69). Rio de Janeiro, RJ: Rios Ambiciosos.

Secchin, L. S. B. (2006). UTI: onde a vida pulsa. Epistemo-somática, 3(2), 223-230. Recuperado de http://pepsic.bvsalud.org/scielo.php?pi$\mathrm{d}=$ S1980-20052006000200006\&script=sci_arttext

Soares, C. P. (2000). Uma tentativa malograda de atendimento em um centro de tratamento intensivo. In M. D. Moura (Org.). Psicanálise e hospital (pp. 41-48). Rio de Janeiro, RJ: Revinter.

Tardivo, R. (2014). Psicanálise na UTI: morte, vida e possíveis interpretações. Jornal de Psicanálise, 47(87), 311-314.

\section{Alinne Nogueira Silva Coppus}

Doutora em Teoria Psicanalítica pela Universidade Federal do Rio de Janeiro, Rio de Janeiro - RJ. Brasil. Docente da Universidade Federal de Juiz de Fora, Juiz de Fora-MG. Brasil.

E-mail: alinnerj@terra.com.br

\section{Marcus Vinícius Rezende Fagundes Netto}

Mestre em psicanálise pela Universidade Estadual do Rio de Janeiro (UERJ). Especialista em Psicologia Hospitalar pela Universidade de São Paulo, São Paulo - SP. Brasil.

E-mail: vinicius.netto@uol.com.br

Endereço para envio de correspondência: Avenida Independência, 2565/ 205, São Mateus. CEP: 36025-290. Juiz de Fora - MG. Brasil.

Recebido 05/03/2012

Reformulado 08/11/2012

Aprovado 15/12/2015

Received 03/05/2012

Reformulated 11/08/2012

Approved 12/15/2015

Recibido 05/03/2012

Reformulada 08/11/2012

Aceptado 15/12/2015 
Psicologia: Ciência e Profissão, 36 (1), 88-100

Como citar: Coppus, A. N. S., \& Netto, M. V. R. F. (2016). A inserção do psicanalista em uma unidade de tratamento intensivo. Psicologia: Ciência e Profissão, 36(1): 88-100. doi:10.1590/1982-3703000322012

How to cite: Coppus, A. N. S., \& Netto, M. V. R. F. (2016). The insertion of the psychoanalyst in an Intensive Care Unit. Psicologia: Ciência e Profissão, 36(1): 88-100. doi:10.1590/1982-3703000322012

Cómo citar: Coppus, A. N. S., \& Netto, M. V. R. F. (2016). La inserción del analista en una Unidad de Cuidado Intensivo. Psicologia: Ciência e Profissão, 36(1): 88-100. doi:10.1590/1982-3703000322012 